\title{
Objective Measurements of Physical Activity and Sedentary Behavior Using Wearable Devices in Patients With Axial Spondyloarthritis: Protocol for a Systematic Review
}

Thomas Carlin ${ }^{1,2}$, MSc; Julie Soulard ${ }^{1,2,3}, \mathrm{PhD}$, PT; Timothée Aubourg ${ }^{1,2}$, PhD; Johannes Knitza ${ }^{1,4}$, MD; Nicolas Vuillerme ${ }^{1,2,5}, \mathrm{PhD}$

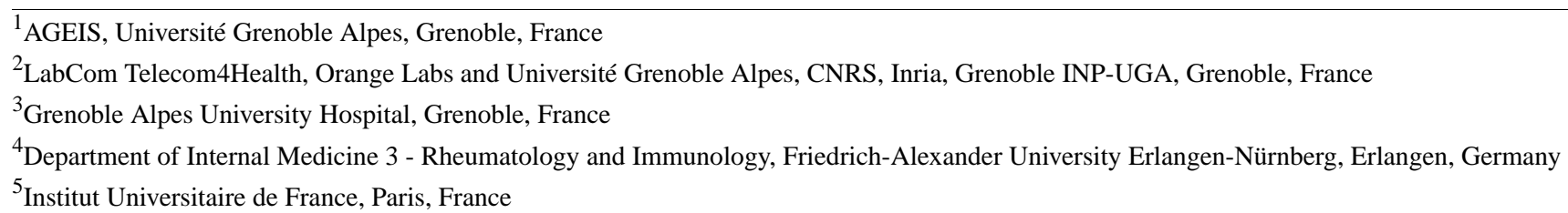

\section{Corresponding Author:}

Nicolas Vuillerme, $\mathrm{PhD}$

AGEIS

Université Grenoble Alpes

Faculty of Medicine

La Tronche, 38706

France

Phone: 33476637104

Email: nicolas.vuillerme@univ-grenoble-alpes.fr

\section{Abstract}

Background: Axial spondyloarthritis (axSpA) is a subgroup of inflammatory rheumatic diseases. Practicing regular exercise is critical to manage pain and stiffness, reduce disease activity, and improve physical functioning, spinal mobility, and cardiorespiratory function. Accordingly, monitoring physical activity and sedentary behavior in patients with axSpA is relevant for clinical outcomes and disease management.

Objective: This review aims to determine which wearable devices, assessment methods, and associated metrics are commonly used to quantify physical activity or sedentary behavior in patients with axSpA.

Methods: The PubMed, Physiotherapy Evidence Database (PEDro), and Cochrane electronic databases will be searched, with no limit on publication date, to identify all the studies matching the inclusion criteria. Only original English-language articles published in a peer-reviewed journal will be included. The search strategy will include a combination of keywords related to the study population, wearable devices, physical activity, and sedentary behavior. We will use the Boolean operators "AND" and "OR" to combine keywords as well as Medical Subject Headings terms.

Results: Search strategy was completed in June 2020 with 23 records obtained. Data extraction and synthesis are currently ongoing. Dissemination of study results in peer-reviewed journals is expected at the end of 2021.

Conclusions: This review will provide a comprehensive and detailed synthesis of published studies that examine the use of wearable devices for objective assessment of physical activity and sedentary behavior in patients with axSpA.

Trial Registration: PROSPERO CRD42020182398; https://www.crd.york.ac.uk/prospero/display_record.php?RecordID=182398 International Registered Report Identifier (IRRID): PRR1-10.2196/23359

(JMIR Res Protoc 2021;10(11):e23359) doi: 10.2196/23359

\section{KEYWORDS}

axial spondyloarthritis; rheumatology; physical activity; sedentary behavior; objective measures; wearable; systematic review 


\section{Introduction}

Axial spondyloarthritis (axSpA) is a subgroup of inflammatory rheumatic diseases that predominantly affect the axial skeleton and the sacroiliac joints [1-3]. Some clinical manifestations of axSpA are inflammatory back pain and spinal stiffness [4-7]. It is now well established that practicing regular exercise results in health benefits in patients with axSpA by managing correctly inflammatory joint diseases [8-10], pain [11], and stiffness [11]; by decreasing disease activity [12]; and by improving physical functioning $[13,14]$, spinal mobility [14,15], and cardiorespiratory function [16]. Interestingly, lack of exercise has been identified as a risk factor for the appearance of depressive symptoms [17], suggesting the benefits of practicing physical activity to manage mental comorbidities of axSpA [17].

Accordingly, monitoring physical activity and sedentary behavior in patients with axSpA is relevant for clinical outcomes and disease management. Traditionally, physical activity and sedentary behavior are assessed using either subjective measures (eg, self-reported questionnaires) [18-27] or objective measures (eg, accelerometers) [23-26,28-31]. At this point, however, recent studies have demonstrated that self-reported physical activity is a less valid and less reliable method for measuring physical activity in patients with axSpA than device-measured physical activity [32,33]. These results support the use of wearable devices for objective assessment of physical activity or sedentary behavior in patients with axSpA [14,32,34-38] as well as in patients with rheumatoid arthritis (eg, [34]). At this point, however, to the best of our knowledge, no systematic review has identified and synthesized the available evidence on the use of wearable devices for this specific population. This review is hence specifically designed to address this issue and, more specifically, to answer the following question: which wearable devices, assessment methods, and associated metrics have been used to quantify physical activity or sedentary behavior in patients with axSpA?

\section{Methods}

\section{Design}

This systematic review will be conducted under the PRISMA (Preferred Reporting Items for Systematic Reviews and Meta-Analyses) guidelines provided by Moher et al [39].

The present review protocol has been registered in PROSPERO (CRD42020182398). This research is exempt from ethics approval because the data are available through published and publicly available resources.

\section{Inclusion Criteria}

All published studies assessing physical activity or sedentary behavior patterns of adults with a diagnosis of axSpA will be included. Only original articles published in English in a peer-reviewed scientific journal will be covered by this review.

The following inclusion criteria will be used:

- Type of participants: All articles including participants aged over 18 years with a diagnosis of axSpA will be included.
- Type of intervention or exposure: Participants are not required to undergo any type of intervention. This review is designed to identify and synthesize current practices of wearable-based monitoring of physical activity or sedentary behavior in patients with axSpA. The effects of the interventions will not be analyzed. Only baseline data on physical activity and sedentary will be extracted.

- Type of outcome measurements: Studies will discuss the use of wearable devices to measure physical activity or sedentary behavior in patients with axSpA.

\section{Exclusion Criteria}

Case reports, abstracts, editorials, conference abstracts, letters to the editor, reviews, and meta-analyses will be excluded from this review. Furthermore, published studies without an objective assessment of physical activity or sedentary behavior of patients with axSpA extracted from wearable devices will be ineligible.

\section{Data Sources and Search Strategy}

The following electronic databases will be systematically searched to identify studies satisfying the search criteria: PubMed, Physiotherapy Evidence Database (PEDro), and Cochrane, with no limit on publication date.

The search strategy includes a combination of the following keywords, using the Boolean operators "AND" and "OR" and Medical Subject Headings terms:

("ankylosing spondylitis" OR spondyloarthritis) AND ("wearable technology" OR "wearable sensor" OR "wearable device" OR "ambulatory monitoring" OR "fitness tracker" OR "activity tracker" OR “activity monitor" OR "step counter" OR Actigraphy OR Pedometer OR "inertial sensor" OR "inertial measurement unit" OR "pendant sensor" OR accelerometer OR inclinometer OR gyroscope) AND ("physical activity" OR "physical activities" OR "physical inactivity" or "physical exertion" OR fitness OR exercise OR sports OR lifetime OR training OR "leisure time" OR "aerobic activity" OR "aerobic activities" OR "activity level” OR Sedentary OR Sedentariness OR "sedentary behaviour" OR "sedentary behaviours" OR "sedentary behavior" OR "sedentary behaviors" OR "sedentary time" OR "sedentary lifestyle" OR "sedentary activity" OR "sedentary activities" OR "prolonged sitting" OR "sitting time" OR seated OR Standing OR walking OR running OR sleep OR Step OR steps OR "covered distance" OR Vo2 or "Maximal oxygen uptake" OR "energy expenditure" OR "moderate- to vigorous-intensity physical activity” OR MVPA).

\section{Study Selection}

Two reviewers (A and B) will independently screen each search match and decide on their potential inclusion based on data extracted from titles, abstracts, and keywords. Subsequently, the full-length text of the potentially included studies will be reviewed in detail to determine whether they satisfy the inclusion criteria mentioned above. Finally, based on inclusion and exclusion criteria, each reviewer (A and $\mathrm{B}$ ) will decide independently on the eligibility of each search match. Any discrepancies between the two reviewers (A and B) will be resolved at a consensus meeting. If disagreement persists, a third reviewer $(\mathrm{C})$ will be consulted to reach a final decision. 


\section{Risk of Bias in Individual Studies}

As our aim is not to evaluate the effect of an intervention, we will not perform a risk of bias assessment. We will conduct a systematic review of published studies that used wearable sensors for objective assessment of physical activity or sedentary behavior in patients with axSpA.

\section{Data Extraction}

In line with PRISMA guidelines [39], a flow chart summarizes each stage of the review with the corresponding number of citations (Figure 1).

Figure 1. PRISMA (Preferred Reporting Items for Systematic Reviews and Meta-Analyses) flow chart of the selection process. PEDro: Physiotherapy Evidence Database.

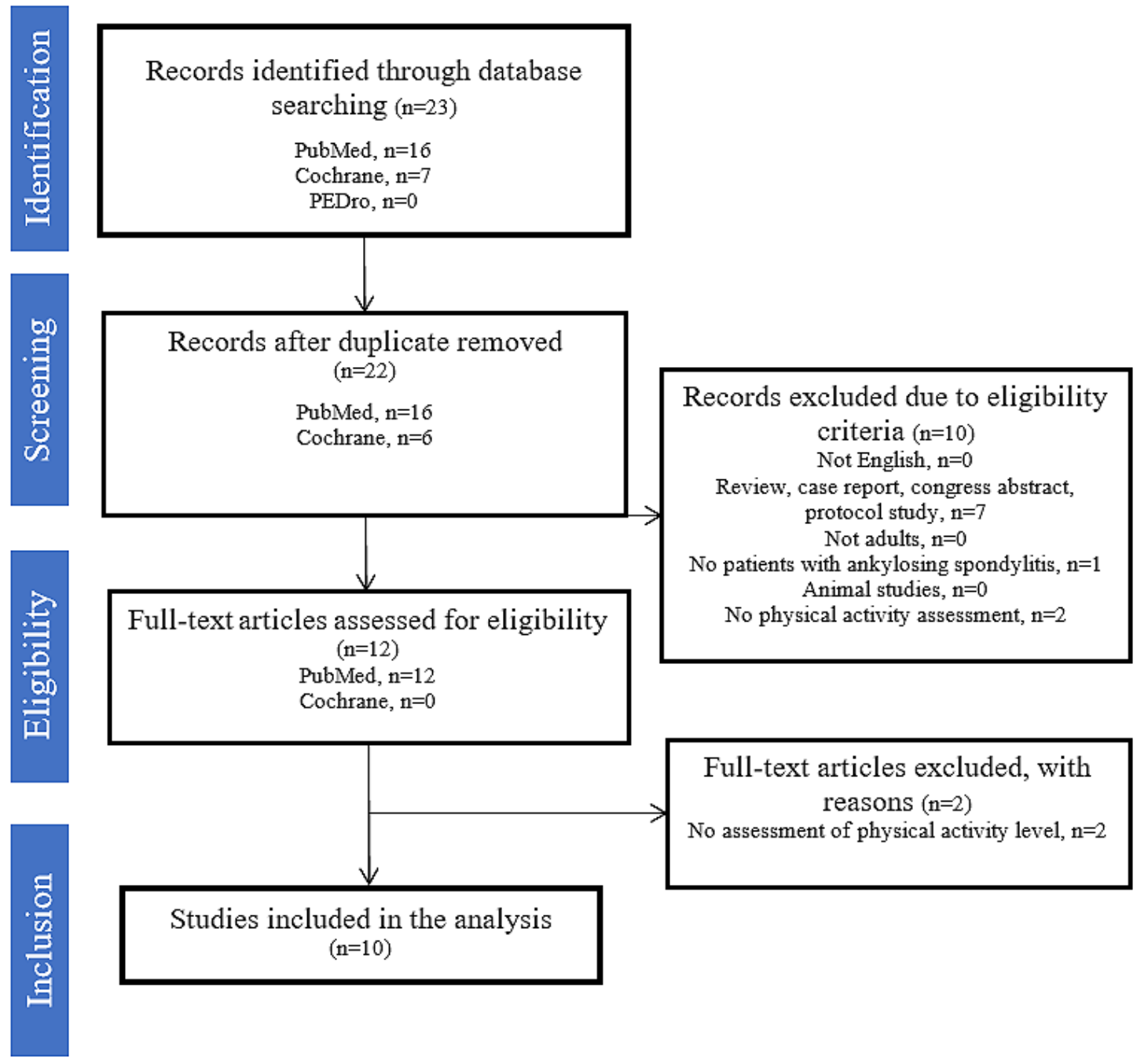

Furthermore, the following 4 data sets will be extracted from the retrieved articles by two independent reviewers:

1. Study characteristics: first author, title, year of publication, journal's name, country, study design, study duration, mention of any adverse events that occurred during the study, and funding.

2. Sample description: sample size, age, gender, weight, height, body mass index, health status, disease duration, functional status measurements, level of pain, description of radiographic damage, biologic medications, Bath Ankylosing Spondylitis Functional Index (BASFI), Bath Ankylosing Spondylitis Activity Index (BASDAI), Bath Ankylosing Spondylitis Metrology Index (BASMI), and fall status.
3. Physical activity and/or sedentary behavior measurement method: measurement tool, protocol, outcome measures.

4. Main results obtained from physical activity and/or sedentary behavior assessment.

\section{Results}

The search using this strategy was completed in June 2020. We obtained a total of 23 records and 22 records after 1 duplicate was removed. A total of 12 full texts were included after screening of the abstracts and titles. Of these, 2 were then excluded after full-text screening, for a total of 10 studies included in the final review (Figure 1). Data extraction and synthesis are ongoing. Naturally, this first preliminary structured search will be repeated before the completion of the final review 
process. Dissemination of the study results in peer-reviewed journals is expected at the end of 2021.

\section{Discussion}

This systematic review is designed to provide a first comprehensive and detailed synthesis of published studies that examine the use of wearable sensors for objective assessment of physical activity or sedentary behavior in patients with axSpA. The strengths of this study are its ability to directly influence future research and clinical care and the fact that this is the first time that a detailed synthesis of published studies in which wearable sensors were used for objective assessment of physical activity or sedentary behavior in patients with axSpA will be conducted. We do believe that our results could help clinicians to choose the most appropriate method to accurately monitor physical activity or sedentary behavior in this population. These results could have a major impact on diagnosis and monitoring in patients with axSpA. Furthermore, this work can guide future studies identifying preferable positions, durations, and environments. This could ultimately enable wearable device-based monitoring systems to find their way into routine clinical assessment and monitoring of patients. A major limitation of this review is the relatively small number of included studies.

The main advantage of a wearable-based monitoring approach is the passive and objective nature of the wearable data. The passive nature creates less burden for patients compared to timely manual completion of patient-reported outcomes. For clinicians, the potential benefit of wearables is related to the continuous, remote, and objective nature of the data. On the other hand, patients may be uncomfortable with continuous surveillance, and this could result in low acceptance of wearable technology despite its benefits. Furthermore, device placement errors could falsify data and lead patients and clinicians to make wrong decisions.

\section{Acknowledgments}

This work was supported by the French National Research Agency in the framework of the Investissements d'avenir program (ANR-10-AIRT-05 and ANR-15-IDEX-02). The sponsors had no involvement in the study or approval of the manuscript for publication. This work forms part of a broader translational and interdisciplinary project, GaitAlps (Nicolas Vuillerme).

\section{Authors' Contributions}

NV designed the systematic review protocol. TC prepared the first draft. All authors reviewed and revised the first draft. All authors read and approved the final manuscript.

\section{Conflicts of Interest}

None declared.

\section{References}

1. Raychaudhuri SP, Deodhar A. The classification and diagnostic criteria of ankylosing spondylitis. J Autoimmun 2014 Feb;48-49:128-133. [doi: 10.1016/j.jaut.2014.01.015] [Medline: 24534717]

2. Rudwaleit M, van der Heijde D, Landewé R, Akkoc N, Brandt J, Chou CT, et al. The assessment of SpondyloArthritis International Society classification criteria for peripheral spondyloarthritis and for spondyloarthritis in general. Ann Rheum Dis 2011 Jan;70(1):25-31. [doi: 10.1136/ard.2010.133645] [Medline: 21109520]

3. Sieper J, Braun J, Rudwaleit M, Boonen A, Zink A. Ankylosing spondylitis: an overview. Ann Rheum Dis 2002 Dec;61 Suppl 3:iii8-ii18 [FREE Full text] [doi: 10.1136/ard.61.suppl 3.iii8] [Medline: 12381506]

4. Sieper J, Poddubnyy D. Axial spondyloarthritis. Lancet 2017 Jul 01;390(10089):73-84. [doi: 10.1016/S0140-6736(16)31591-4] [Medline: 28110981]

5. Sieper J, Rudwaleit M, Baraliakos X, Brandt J, Braun J, Burgos-Vargas R, et al. The Assessment of SpondyloArthritis international Society (ASAS) handbook: a guide to assess spondyloarthritis. Ann Rheum Dis 2009 Jun;68 Suppl 2:ii1-ii44. [doi: 10.1136/ard.2008.104018] [Medline: 19433414]

6. Sağ S, Nas K, Sağ MS, Tekeoğlu, Kamanlı A. Relationship of work disability between the disease activity, depression and quality of life in patients with ankylosing spondylitis. J Back Musculoskelet Rehabil 2018;31(3):499-505. [doi: 10.3233/BMR-169657] [Medline: 29504521]

7. Imkamp M, Lima Passos V, Boonen A, Arends S, Dougados M, Landewé R, et al. Uncovering the heterogeneity of disease impact in axial spondyloarthritis: bivariate trajectories of disease activity and quality of life. RMD Open 2018;4(2):e000755 [FREE Full text] [doi: 10.1136/rmdopen-2018-000755] [Medline: 30487997]

8. van der Heijde D, Ramiro S, Landewé R, Baraliakos X, Van den Bosch F, Sepriano A, et al. 2016 update of the ASAS-EULAR management recommendations for axial spondyloarthritis. Ann Rheum Dis 2017 Jan 13;76(6):978-991. [doi: 10.1136/annrheumdis-2016-210770] [Medline: 28087505]

9. Braun J, van den Berg R, Baraliakos X, Boehm H, Burgos-Vargas R, Collantes-Estevez E, et al. 2010 update of the ASAS/EULAR recommendations for the management of ankylosing spondylitis. Ann Rheum Dis 2011 May 02;70(6):896-904. [doi: 10.1136/ard.2011.151027] [Medline: 21540199] 
10. Dagfinrund H, Hagen K, Kvien T. Physiotherapy interventions for ankylosing spondylitis. Cochrane Database of Systematic Reviews 2004(4):CD002822. [doi: 10.1002/14651858.cd002822.pub2]

11. Reveille JD, Weisman MH. The epidemiology of back pain, axial spondyloarthritis and HLA-B27 in the United States. Am J Med Sci 2013 Jun;345(6):431-436 [FREE Full text] [doi: 10.1097/maj.0b013e318294457f] [Medline: 23841117]

12. Brophy S, Cooksey R, Davies H, Dennis MS, Zhou S, Siebert S. The effect of physical activity and motivation on function in ankylosing spondylitis: a cohort study. Semin Arthritis Rheum 2013 Jun;42(6):619-626 [FREE Full text] [doi: 10.1016/j.semarthrit.2012.09.007] [Medline: 23351615]

13. O'Dwyer T, O'Shea F, Wilson F. Physical activity in spondyloarthritis: a systematic review. Rheumatol Int 2015 Mar;35(3):393-404. [doi: 10.1007/s00296-014-3141-9] [Medline: 25300728]

14. Coulter EH, McDonald MT, Cameron S, Siebert S, Paul L. Physical activity and sedentary behaviour and their associations with clinical measures in axial spondyloarthritis. Rheumatol Int 2020 Mar;40(3):375-381 [FREE Full text] [doi: 10.1007/s00296-019-04494-3] [Medline: 31848736]

15. Levitova A, Hulejova H, Spiritovic M, Pavelka K, Senolt L, Husakova M. Clinical improvement and reduction in serum calprotectin levels after an intensive exercise programme for patients with ankylosing spondylitis and non-radiographic axial spondyloarthritis. Arthritis Res Ther 2016 Nov 25;18(1):275 [FREE Full text] [doi: 10.1186/s13075-016-1180-1] [Medline: 27887637]

16. Zão A, Cantista P. The role of land and aquatic exercise in ankylosing spondylitis: a systematic review. Rheumatol Int 2017 Dec;37(12):1979-1990. [doi: 10.1007/s00296-017-3829-8] [Medline: 28983663]

17. Redeker I, Hoffmann F, Callhoff J, Haibel H, Sieper J, Zink A, et al. Determinants of psychological well-being in axial spondyloarthritis: an analysis based on linked claims and patient-reported survey data. Ann Rheum Dis 2018 Jul;77(7):1017-1024 [FREE Full text] [doi: 10.1136/annrheumdis-2017-212629] [Medline: 29525776]

18. Kayes NM, McPherson KM. Measuring what matters: does 'objectivity' mean good science? Disabil Rehabil 2010;32(12):1011-1019. [doi: 10.3109/09638281003775501] [Medline: 20384538]

19. van Boxtel MP, Langerak K, Houx PJ, Jolles J. Self-reported physical activity, subjective health, and cognitive performance in older adults. Exp Aging Res 1996 Sep 27;22(4):363-379. [doi: 10.1080/03610739608254017] [Medline: $\underline{8968708]}$

20. Baecke J, Burema J, Frijters J. A short questionnaire for the measurement of habitual physical activity in epidemiological studies. Am J Clin Nutr 1982 Nov 01;36(5):936-942. [doi: 10.1093/ajen/36.5.936] [Medline: 7137077]

21. InterAct Consortium, Peters T, Brage S, Westgate K, Franks PW, Gradmark A, et al. Validity of a short questionnaire to assess physical activity in 10 European countries. Eur J Epidemiol 2012 Jan;27(1):15-25 [FREE Full text] [doi: 10.1007/s10654-011-9625-y] [Medline: 22089423]

22. Sallis JF, Saelens BE. Assessment of physical activity by self-report: status, limitations, and future directions. Res Q Exerc Sport 2000 Jun;71(2 Suppl):S1-14. [Medline: 10925819]

23. Welk G, editor. Physical activity assessments for health-related research. Champaign, IL: Human Kinetics; 2002:1-280.

24. Kang M, Rowe DA. Issues and challenges in sedentary behavior measurement. Meas Phys Educ Exerc Sci 2015 Aug 19;19(3):105-115. [doi: 10.1080/1091367x.2015.1055566]

25. Bond DS, Thomas JG, Unick JL, Raynor HA, Vithiananthan S, Wing RR. Self-reported and objectively measured sedentary behavior in bariatric surgery candidates. Surg Obes Relat Dis 2013;9(1):123-128 [FREE Full text] [doi: 10.1016/j.soard.2012.09.008] [Medline: 23265767]

26. Hart TL, Ainsworth BE, Tudor-Locke C. Objective and subjective measures of sedentary behavior and physical activity. Med Sci Sports Exerc 2011 Mar;43(3):449-456. [doi: 10.1249/MSS.0b013e3181ef5a93] [Medline: 20631642]

27. Sternfeld B, Goldman-Rosas L. A systematic approach to selecting an appropriate measure of self-reported physical activity or sedentary behavior. J Phys Act Health 2012 Jan;9 Suppl 1:S19-S28. [doi: 10.1123/jpah.9.s1.s19] [Medline: 22287444]

28. Blair SN, Haskell WL. Objectively measured physical activity and mortality in older adults. JAMA 2006 Jul 12;296(2):216-218. [doi: 10.1001/jama.296.2.216] [Medline: 16835428]

29. LaPorte RE, Kuller L, Kupfer D, McPartland RJ, Matthews G, Caspersen C. An objective measure of physical activity for epidemiologic research. Am J Epidemiol 1979 Feb;109(2):158-168. [doi: 10.1093/oxfordjournals.aje.a112671] [Medline: 425955]

30. Vanhees L, Lefevre J, Philippaerts R, Martens M, Huygens W, Troosters T, et al. How to assess physical activity? How to assess physical fitness? Eur J Cardiovasc Prev Rehabil 2005 Apr;12(2):102-114. [doi: 10.1097/01.hjr.0000161551.73095.9c] [Medline: 15785295$]$

31. Harris TJ, Owen CG, Victor CR, Adams R, Cook DG. What factors are associated with physical activity in older people, assessed objectively by accelerometry? Br J Sports Med 2009 Jun;43(6):442-450. [doi: 10.1136/bjsm.2008.048033] [Medline: 18487253]

32. Arends S, Hofman M, Kamsma YP, van der Veer E, Houtman PM, Kallenberg CG, et al. Daily physical activity in ankylosing spondylitis: validity and reliability of the IPAQ and SQUASH and the relation with clinical assessments. Arthritis Res Ther 2013 Aug 23;15(4):R99 [FREE Full text] [doi: 10.1186/ar4279] [Medline: 23971767]

33. Prince SA, Adamo KB, Hamel ME, Hardt J, Connor Gorber S, Tremblay M. A comparison of direct versus self-report measures for assessing physical activity in adults: a systematic review. Int J Behav Nutr Phys Act 2008 Nov 06;5:56 [FREE Full text] [doi: 10.1186/1479-5868-5-56] [Medline: 18990237] 
34. Jacquemin C, Servy H, Molto A, Sellam J, Foltz V, Gandjbakhch F, et al. Physical activity assessment using an activity tracker in patients with rheumatoid arthritis and axial spondyloarthritis: prospective observational study. JMIR mHealth uHealth 2018 Jan 02;6(1):e1 [FREE Full text] [doi: 10.2196/mhealth.7948] [Medline: 29295810]

35. Plasqui G, Boonen A, Geusens P, Kroot EJ, Starmans M, van der Linden S. Physical activity and body composition in patients with ankylosing spondylitis. Arthritis Care Res (Hoboken) 2012 Jan;64(1):101-107 [FREE Full text] [doi: 10.1002/acr.20566] [Medline: 22213726]

36. Niedermann K, Sidelnikov E, Muggli C, Dagfinrud H, Hermann M, Tamborrini G, et al. Effect of cardiovascular training on fitness and perceived disease activity in people with ankylosing spondylitis. Arthritis Care Res (Hoboken) 2013 Nov;65(11):1844-1852 [FREE Full text] [doi: 10.1002/acr.22062] [Medline: 23836515]

37. Swinnen TW, Scheers T, Lefevre J, Dankaerts W, Westhovens R, de Vlam K. Physical activity assessment in patients with axial spondyloarthritis compared to healthy controls: a technology-based approach. PLoS One 2014;9(2):e85309 [FREE Full text] [doi: 10.1371/journal.pone.0085309] [Medline: 24586239]

38. Fongen C, Halvorsen S, Dagfinrud H. High disease activity is related to low levels of physical activity in patients with ankylosing spondylitis. Clin Rheumatol 2013 Dec;32(12):1719-1725. [doi: 10.1007/s10067-013-2320-5] [Medline: 23900575]

39. Moher D, Liberati A, Tetzlaff J, Altman DG, PRISMA Group. Preferred reporting items for systematic reviews and meta-analyses: the PRISMA statement. PLoS Med 2009 Jul 21;6(7):e1000097 [FREE Full text] [doi: 10.1371/journal.pmed.1000097] [Medline: 19621072]

\author{
Abbreviations \\ axSpA: axial spondyloarthritis \\ BASDAI: Bath Ankylosing Spondylitis Functional Index \\ BASFI: Bath Ankylosing Spondylitis Functional Index \\ BASMI: Bath Ankylosing Spondylitis Metrology Index \\ PEDro: Physiotherapy Evidence Database \\ PRISMA: Preferred Reporting Items for Systematic Reviews and Meta-Analyses
}

Edited by G Eysenbach; submitted 10.08.20; peer-reviewed by C Romanzini, G Murdaca, X Ji, H Zihao, G Burmester; comments to
author 03.02.21; revised version received 24.05.21; accepted 30.06.21; published 25.11.21
Please cite as:
Carlin T, Soulard J, Aubourg T, Knitza J, Vuillerme N
Objective Measurements of Physical Activity and Sedentary Behavior Using Wearable Devices in Patients With Axial Spondyloarthritis:
Protocol for a Systematic Review
JMIR Res Protoc $2021 ; 10(11): e 23359$
URL: https://www.researchprotocols.org/2021/11/e23359
doi: $10.2196 / 23359$
PMID:

(C)Thomas Carlin, Julie Soulard, Timothée Aubourg, Johannes Knitza, Nicolas Vuillerme. Originally published in JMIR Research Protocols (https://www.researchprotocols.org), 25.11.2021. This is an open-access article distributed under the terms of the Creative Commons Attribution License (https://creativecommons.org/licenses/by/4.0/), which permits unrestricted use, distribution, and reproduction in any medium, provided the original work, first published in JMIR Research Protocols, is properly cited. The complete bibliographic information, a link to the original publication on https:/www.researchprotocols.org, as well as this copyright and license information must be included. 